\title{
Editorial to selected papers from the IMEKO TC21 Conference AMCTM 2017
}

\author{
Franco Pavese \\ TC21 Chair, IMEKO, Torino, Italy
}

Section: EDITORIAL

Citation: Franco Pavese, Editorial to selected papers from the IMEKO TC21 Conference AMCTM 2017, Acta IMEKO, vol. 7, no. 2, article 10, June 2018, identifier: IMEKO-ACTA-07 (2018)-02-10

Editor: Dušan Agrež, University of LUBLANA, Slovenia

Received June 22, 2018; In final form June 22, 2018; Published June 2018

Copyright: @ 2018 IMEKO. This is an open-access article distributed under the terms of the Creative Commons Attribution 3.0 License, which permits unrestricted use, distribution, and reproduction in any medium, provided the original author and source are credited

Corresponding author: Franco Pavese, email: frpavese@gmail.com

Dear Reader,

this Special Issue includes five papers, originating from subject matters presented at the IMEKO TC21 International Conference AMCTM 2017 held in Glasgow in 2017 and selected for publication in ACTA IMEKO.

The initial paper is a review about how knowledge is gained progressively and about where, in this process, the intercomparisons are an essential step.

The paper of Shestakov is an ample review of the viewpoint of a Russian major University about dynamic measurement.

The paper of Miller et al. concerns a problem in LargeVolume Metrology (LVM) manufacturing, where the uncertainty must be evaluated in the frame of optical-based metrology.

The paper of Franceschini and Maisano illustrates, also in the frame of LVM systems, a new mathematical/statistical model for the real-time localization of the probe.

The paper of Shestakov et al. proposes basic ideas for the mathematical modelling of optimal dynamic measurements, the key issue being the construction of a mathematical model of the measuring transducer.

Franco Pavese

IMEKO TC21, Chair 